Postprint of Journal of Physical Chemistry C, 2016, 120, 28753-28761. DOI: 10.1021/acs.jpcc.6b09601

\title{
Synthesis and Characterization of V-doped $\beta-\operatorname{In}_{2} S_{3}$ Thin Films on FTO Substrates
}

Cristina Tapia ${ }^{\mathrm{a}}$, Sean P. Berglund $\mathrm{d}^{\mathrm{b}}$, Dennis Friedrich ${ }^{\mathrm{b}}$, Thomas Dittrich ${ }^{\mathrm{b}}$, Peter Bogdanoff $\mathrm{f}^{\mathrm{b}}$, Yang Liu ${ }^{c, d}$, Sergiu Levcenko ${ }^{b}$, Thomas Unold ${ }^{b}$, José Carlos Conesa ${ }^{a}$, Antonio L. de Lacey ${ }^{a}$, Marcos Pita ${ }^{\mathrm{a} *}$, Sebastian Fiechter ${ }^{\mathrm{b} *}$

a Instituto de Catalisis y Petroleoquimica, CSIC. C/ Marie Curie, 2, L10. 28049 Madrid, Spain.

${ }^{\mathrm{b}}$ Helmholtz-Zentrum Berlin für Materialien und Energie GmbH, Institute for Solar Fuels,

${ }^{\mathrm{c}}$ Helmholtz-Zentrum Berlin für Materialien und Energie GmbH, Nanooptical Concepts for PV, Hahn-Meitner-Platz 1, 14109 Berlin, Germany.

${ }^{d}$ Freie Universität Berlin, Institut für Chemie, Fabeckstr. 34-36, 14195 Berlin, Germany

\begin{abstract}
Intermediate band semiconductors have raised interest as materials to both enhance photovoltaics' efficiency and promote photocatalytic activity driven by visible light. The present work shows the synthesis of $\operatorname{In}_{2} S_{3}$ doped with four different ratios of V using ILGAR technique. This nebulize-spray based technique allows the deposition of $\operatorname{In}_{2}(\mathrm{~V}) \mathrm{S}_{3}$ thin layers controlling the layer thickness and providing high reliability on sample preparation. The samples have been characterized by X-ray diffraction, electron microscopy, profilometry, UV-Vis spectroscopy, inductively coupled plasma mass spectrometry, X-ray photoemission spectroscopy, surface photovoltage spectroscopy, time-resolved microwave conductivity, photoelectrochemical measurements and electrochemical impedance spectroscopy. An optimum of $1.4 \% \mathrm{~V}$ content yielded the highest enhancement of both photocurrent density and photoluminescence compared to undoped $\mathrm{In}_{2} \mathrm{~S}_{3}$. The results suggest that the inclusion of $\mathrm{V}$ in the $\mathrm{In}_{2} \mathrm{~S}_{3}$ at $1.4 \%$ yields a high amount of in-gap levels within the crystalline structure that causes a Fermi energy level shift, which also induces the shift of the level of both valence and conduction band.
\end{abstract}

\section{INTRODUCTION}

Harvesting energy from the sunlight has been a matter of research for both, its direct conversion to electricity (via photovoltaic solar cells) and its photochemical possibilities (i.e. photocatalytic processes). One strategy that can be used to boost the energy collected in the photoabsorption process is the addition of dopants to semiconductor materials. Dopants cause several effects on the hosting materials. The most typical effect is influencing the energy band structure of the hosting semiconductor, broadly known for $\mathrm{TiO}_{2}$ or $\mathrm{ZnO}^{1-3} \mathrm{In}$ some specific cases the dopant alters the energy level structure of the pure material and causes the appearance of an intermediate band in its structure. Intermediate band semiconductors became popular few decades 
ago ${ }^{2,3}$ although they were firstly described in $1960 .{ }^{4}$ Such intermediate band allows the successful excitation of electrons from the valence band (VB) to the conduction band (CB) in two steps with photons of energy lower than the fundamental of the host material band gap. The first step requires a photon with enough energy to excite a valence electron to the intermediate level while the second step requires another photon with energy to excite the electron again to the CB. In theory this feature allows solar cell efficiencies above $60 \%$.

Based on simulations chalcogenides have been proposed as suitable materials to host an intermediate band by using transition metals as dopants. Such is the case for Ti-substituted III-V semiconductors, ${ }^{7}$ Ti- and Cr-substituted $\mathrm{CuGaS}_{2}$ chalcopyrite, ${ }^{8}$ and $\mathrm{SnS}_{2}, \mathrm{In}_{2} \mathrm{~S}_{3}$ or $\mathrm{MgIn}_{2} \mathrm{~S}_{4}$ partially substituted by V.,10 Some of these materials have also been experimentally synthesized. ${ }^{11,12} \mathrm{In}_{2} \mathrm{~S}_{3}$ is a particularly interesting material. ${ }^{13} \beta-\mathrm{In}_{2} \mathrm{~S}_{3}$ has recently been studied as buffer layer in photovoltaic solar cells because it results in a conversion efficiency very close to CdS, but it is less toxic. ${ }^{14} \beta-\operatorname{In}_{2} S_{3}$ can also play a role in photocatalytic reactions. Advantages of $\beta$ - $\mathrm{In}_{2} \mathrm{~S}_{3}$ for its use as photocatalyst are its band gap energy $\left(\mathrm{E}_{\mathrm{g}} \approx 2-2.3 \mathrm{eV}\right)$ and its photoconductivity. ${ }^{14-16} \beta-\operatorname{In}_{2} S_{3}$ is an n-type semiconductor with a defect spinel structure where $\mathrm{In}^{3+}$ occupies tetrahedral positions and $\mathrm{S}^{2-}$ occupies the octahedral positions, or a flowerlike cubic form. ${ }^{17}$ It has also been demonstrated that $\beta$ - $\operatorname{In}_{2} S_{3}$, when properly doped with $V$, can yield an intermediate band when synthesized by a hydrothermal route. ${ }^{18}$ However, to our knowledge Vdoped $\beta$ - $\operatorname{In}_{2} S_{3}$ has never been synthesized as a thin film on a conductive support.

In this work we demonstrate the deposition and characterization of pure $\beta-\operatorname{In}_{2} S_{3}$ and $V$ doped $\beta$ $\mathrm{In}_{2} \mathrm{~S}_{3}$ thin films. Both kinds of thin films were deposited by the Spray Ion Layer Gas Reaction (Spray-ILGAR) technique; ${ }^{19-21}$ ILGAR consists on the nebulization of ionic precursors followed by its gas transport to the heated substrate, where the reaction takes place. In the present paper, the charge transfer properties of both materials have been characterized using surface photovoltage spectroscopy (SPV) and time resolved microwave conductivity (TRMC). SPV provides information regarding the photo-generation of excess charge carriers, their separation/transport in the bulk and their recombination rate. SPV signals correlate to the specific region of the material where charge carriers are generated and separated, providing information about electronic surface states in the bulk and at the different regions measured. ${ }^{21}$ TRMC is a non-invasive technique that determines the sample photoconductivity providing information about the mobility and lifetime of the charge carriers. The photoelectrochemical properties of the material were determined using chronoamperometry under simulated solar radiation, whereas impedance spectroscopy was used to measure the flat-band potential and incident photon to current conversion efficiency (ICPE) was measured to determine the dependency of the photocurrent density on the incident photon energy.

\section{EXPERIMENTAL SECTION}

Experimental procedures: deposition and characterization

Reagents. All the reagents were used as received without further purification. Indium acetylacetonate $\left(\mathrm{In}(\mathrm{acac})_{3}\right)$, vanadium acetylacetonate $\left(\mathrm{V}(\mathrm{acac})_{3}\right)$ and ethanol were purchased from Sigma-Aldrich. Fluorine-doped tin oxide (FTO) cloated glass substrates $(\sim 8 \Omega / \mathrm{sq})$ were received from Solaronix. Sodium carbonate, sodium sulfite and sodium acetate were purchased from Panreac. Gases used were $\mathrm{H}_{2} \mathrm{~S}\left(5 \%\right.$ in nitrogen $\left.\left(\mathrm{N}_{2}\right)\right)$ and pure $\mathrm{N}_{2}$. 
Deposition of $\beta$-In $\mathrm{I}_{2} S_{3}$ and $V$-doped $\beta$-In $\mathrm{I}_{2} S_{3}$ films. A typical spray-ILGAR set up was used for the deposition of $\beta$-In $\mathrm{In}_{2} \mathrm{~S}_{3}$ and V-doped $\beta$-In ${ }_{2} \mathrm{~S}_{3}$ films. ${ }^{19}$ FTO coated glasses and quartz glasses were used as substrates for the deposition. The temperature of the substrates was kept at $225{ }^{\circ} \mathrm{C}$ during the deposition process. The process and mechanism of $\beta-\operatorname{In}_{2} S_{3}$ film deposition have been reported previously. ${ }^{19-21}$ In this work, the sequential and cyclic Spray-ILGAR process consists of four steps. First, a solution of $\operatorname{In}(\mathrm{acac})_{3} 25 \mathrm{mM}$ in ethanol was nebulized to form an aerosol, Which was blown by $\mathrm{N}_{2}$ gas onto the heated substrate. The $\mathrm{H}_{2} \mathrm{~S}$ (g) flow-rate was 15-20 $\mathrm{mL} / \mathrm{min}$ and lasted for 50 seconds. In the second step, the nebulization and $\mathrm{H}_{2} \mathrm{~S}$ flow were stopped for 10 seconds. After that, the $\mathrm{H}_{2} \mathrm{~S}$ flow was introduced into the reaction chamber to react with the film deposited on the heated substrate for 20 seconds. Finally, the $\mathrm{H}_{2} \mathrm{~S}$ gas flow was stopped. Afterwards, $\mathrm{N}_{2}$ gas flow was used to serve as a purging step for 10 seconds. During all the steps, the $\mathrm{N}_{2}$ carrier gas flow was set at a constant flow-rate of $5 \mathrm{~L} / \mathrm{min}$. These steps of the spray-ILGAR cycle were repeated until the desired film thickness was obtained.

Different thicknesses of $\beta$ - $\operatorname{In}_{2} S_{3}$ films were obtained by repeating the Spray-ILGAR cycles 6, 9, 12, 15, 18 or 21 times. These films were used to study influence of the thickness on the optical properties of $\operatorname{In}_{2} S_{3}$. V-doped $\beta$ - $\operatorname{In}_{2} S_{3}$ films were deposited by adding 4 different concentrations of $\mathrm{V}(\mathrm{acac})_{2}(0.5,1,2$ and $10 \mathrm{mM})$ into the $\mathrm{In}(\mathrm{acac})_{3}$ and ethanol solution and applying 9 SprayILGAR cycles for each case. The process yielded different V percentages: $0.7 \% \mathrm{~V}, 1 \% \mathrm{~V}, 1.4 \%$ $\mathrm{V}$ and 3.4\% V respectively. In the case of using quartz substrates, 15 ILGAR cycles were applied for the deposition of $\beta$ - $\operatorname{In}_{2} S_{3}$ or V-doped $\beta$ - $\operatorname{In}_{2} S_{3}$ thin films.

\section{Characterization techniques}

X-ray diffraction (XRD) of $\beta$ - $\operatorname{In}_{2} S_{3}$ and V-doped $\beta$ - $\operatorname{In}_{2} S_{3}$ was performed with a Bruker D8 Advance $\mathrm{X}$-ray diffractometer $\left(\mathrm{Co}-\mathrm{K}_{\alpha}, \lambda=0.178897 \mathrm{~nm}\right)$ equipped with a LynxEye detector in a Bragg-Brentano configuration. The diffractograms were directly measured using the layers as deposited on the FTO glass substrates as grown.

Scanning electron microscopy (SEM) of the as grown layers was performed using a JEOL JSM 6500F scanning electron microscope.

Transmission electron microscopy (TEM) was applied at a point resolution of $0.19 \mathrm{~nm}$ with a 200 KV JEOL 2100 transmission electron microscope, equipped with an Oxford Instruments EDX analyzer. The sample was prepared as follows: a FTO glass substrate modified with $1 \% \mathrm{~V}$-doped $\beta$-In ${ }_{2} S_{3}$ was scratched, taking the material powder into an ethanol-filled Eppendorf cap. The sample was immersed for $15 \mathrm{~min}$ in an ultrasonic bath. $20 \mu \mathrm{L}$ of the sample was deposited on a carbon film coated 200 mesh copper TEM grid (Electron Microscopy Sciences) and let to dry.

The thickness of the $\beta-\operatorname{In}_{2} S_{3}$ and $V$-doped $\beta$ - $\operatorname{In}_{2} S_{3}$ thin films, including variation, was analyzed using a DEKTAK 8 Advanced Development Profiler (Veeco Instruments).

Inductively coupled plasma mass spectrometry (ICP-MS) was performed using a Hewlett Packard 4500 Series Shield Torch System spectrometer. The samples were measured without any further treatment after film deposition.

UV-vis spectra of the modified substrates were measured using a Perkin Elmer Lambda 950 spectrometer equipped with an integrating sphere. 
The surface of the thin layer samples was characterized by X-Ray photoelectron spectroscopy (XPS). XPS measurements were carried out with a monochromatic Al $\mathrm{K}_{\alpha}$ source (Specs Focus 500) and a hemispherical analyzer (Specs Phoibos 100) in an Ultra High Vacuum system with a base pressure in the low $10^{-8}$ mbar range.

Surface photovoltage spectroscopy (SPV). SPV measurements were performed at room temperature under ambient pressure conditions. The SPV setup and measurement protocol have been described previously. ${ }^{20-22}$ The modulated SPV signals were measured using a fixed capacitor mode. The samples were illuminated with a halogen lamp emitting in the photon energy range of 0.4 to $4 \mathrm{eV}$; wavelengths were selected using a quartz prism monochromator. The monochromatic radiation was chopped at a frequency of $8 \mathrm{~Hz}$ before illuminating the sample, and the SPV signal was detected with a double-phase lock-in-amplifier (EG \& G, 7260 DSP). ${ }^{21,22}$ SPV measurements were performed for all the samples.

Time-resolved microwave conductivity (TRMC) measurements were performed by mounting the pure and $\mathrm{V}$ doped $\beta$ - $\mathrm{In}_{2} \mathrm{~S}_{3}$ samples on quartz substrates in a microwave cavity cell which was placed within a set-up similar to the one described elsewhere. ${ }^{23,24}$ The X-band $(8.2-12.4 \mathrm{GHz})$ microwaves were generated using a voltage controlled oscillator (SiversIMA VO3262X). The resonance frequency of the loaded cavity containing the sample was determined by measuring the reflected power as a function of microwave frequency which was normalized with respect to the power measured for a fully reflecting copper end plate. From the resulting resonance curve the resonance frequency $f_{0}$, corresponding to minimum reflected power and maximum electric field strength within the cavity, was found to be $8.52 \mathrm{GHz}$ for our $\mathrm{In}_{2} \mathrm{~S}_{3}$ films. During the measurements, a change in the microwave power reflected by the cavity upon sample excitation by 6 ns (full-width at half-maximum) pulses of a frequency-doubled Q-switched Nd:YAG laser at a wavelength of $532 \mathrm{~nm}(10 \mathrm{~Hz}$ repetition rate), $\Delta \mathrm{P} / \mathrm{P}$ was monitored and correlated to the photoinduced change in the conductance of the sample, $\Delta \mathrm{G}$, by

$$
\frac{\Delta P}{P}(t)=-K \Lambda G(t)
$$

where $\mathrm{K}$ is the sensitivity factor derived from the resonance characteristics of the cavity and the dielectric properties of the medium. From the experimentally observed change in the photoconductance, the product of the charge carrier generation yield $(\varphi)$ and the sum of electron and hole mobilities $(\Sigma \mu)$ can be obtained according to

$$
\phi \Sigma \mu=\frac{\Delta G}{l_{0} \beta \Theta F_{A}}
$$

where $I_{0}$ is the incident intensity per pulse, e is the elementary charge, $\beta$ is the ratio between the inner broad and narrow dimensions of the waveguide, and $\mathrm{F}_{\mathrm{A}}$ is the fraction of incident photons absorbed within the sample.

The photoluminescence (PL) measurements were performed using a laser diode (409nm) and a $1 / 2 \mathrm{~m}$ grating monochromator equipped with a liquid $\mathrm{N}_{2}$ cooled linear InGaAs diode array and thermoelectrically cooled CCD array detectors. The PL temperature-dependent measurements were conducted in a closed-cycle helium cryostat. 
Electrochemical and photoelectrochemical characterization was performed using a threeelectrode cell configuration using an aqueous electrolyte containing $0.1 \mathrm{M}$ sodium carbonate, 0.1 $\mathrm{M}$ sodium acetate and $0.2 \mathrm{M}$ sodium sulfite at $\mathrm{pH}$ 7. A coiled $\mathrm{Pt}$ wire was used as counter electrode, and $\mathrm{Ag} / \mathrm{AgCl}(3 \mathrm{M} \mathrm{KCl})$ as reference electrode. Bias voltage to the working electrode was applied via an electrical contact to the uncoated part of the FTO glass substrate. A surface area of $0.283 \mathrm{~cm}^{2}$ of the deposited film was in contact with the electrolyte. Photocurrent measurements were recorded using an EG\&G PRINCETON Applied Research Model 273A potentiostat under white light illumination from a solar simulator (WACOM, type WXS-505-5H) calibrated to match the AM 1.5 spectrum $\left(100 \mathrm{~mW} / \mathrm{cm}^{2}\right)$.

\section{RESULTS AND DISCUSSION}

The thin films investigated in the present study were synthesized by the spray-ILGAR, which is characterized by a sequential and cyclic process to deposit thin layers of metal chalcogenides.

During the first step of the spray-ILGAR cycle the metal ion containing precursor solution is ultrasonicated to form a mist of droplets. Next the cations dissolved in the mist of droplets are transported via $\mathrm{H}_{2} \mathrm{~S}$ gas flow to a hot substrate surface $\left(225^{\circ} \mathrm{C}\right)$, where a chalcogenide film is formed by reaction of the metal ions with $\mathrm{H}_{2} \mathrm{~S}$. $\mathrm{In}_{2} \mathrm{~S}_{3}$ has been studied as a buffer layer for chalcopyrite thin film solar cells, but so far it has not been studied as a photoactive semiconductor alone. For that reason, this work focuses on the preparation and characterization of $\mathrm{In}_{2} \mathrm{~S}_{3}$ thin films, doped and undoped, employed as a standalone photoelectrodes. $\beta-\operatorname{In}_{2} \mathrm{~S}_{3}$ layers of different thicknesses were obtained by repeating the ILGAR cycles a various number of times. The obtained thicknesses were measured using a DEKTAK surface profilometer. It was found that the thickness of the thin layer increased roughly in proportion with the number of deposition cycles: 6 cycles yielded a 100nm thick layer, 9 cycles was $350 \mathrm{~nm}, 15$ cycles was 700nm, 18 cycles was $910 \mathrm{~nm}$, and 21 cycles was $970 \mathrm{~nm}$. To prepare V-doped layers 9 cycles were used with different concentrations of vanadium in the precursor solution $(0.5,1,2$ and $10 \mathrm{mM} \mathrm{V(acac})_{2}$ ) yielding approximately $350 \mathrm{~nm}$ thick layer each. The resulting layers contained an increasing ratio of $\mathrm{V}$ :In. The content of $\mathrm{V}$ was measured by ICP-MS, corresponding to $0.7 \%$, $1.0 \%$ and $1.4 \%$ and $3.4 \%$, respectively.

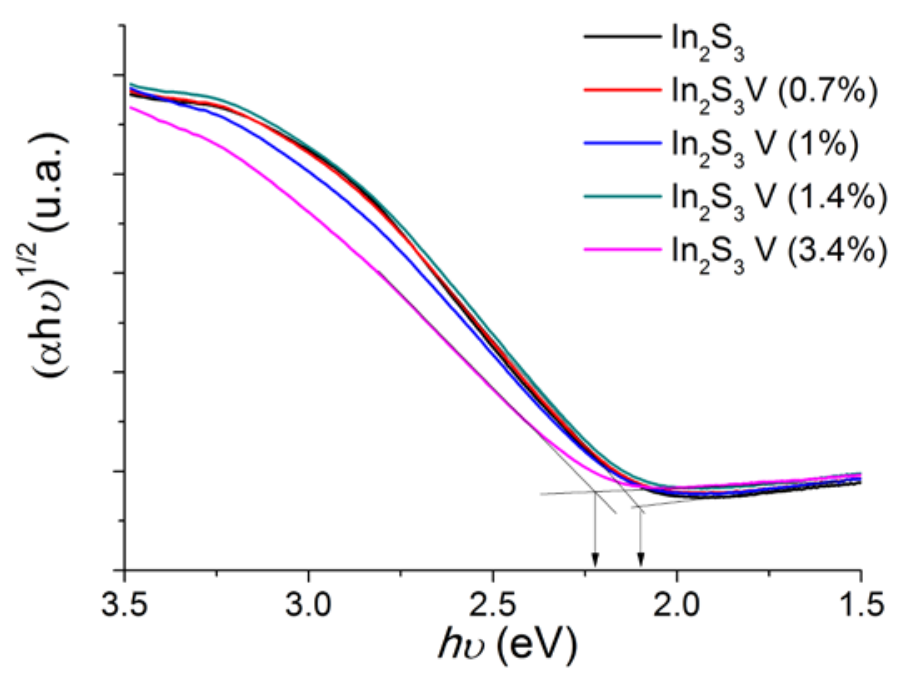


Figure 1. Plot of $(\alpha h v)^{1 / 2}$ vs. hv indicating the presence of an indirect band gap of the samples shown in A.

The crystal structure of the resulting $\beta$ - $\operatorname{In}_{2} S_{3}$ and V-doped $\beta-\operatorname{In}_{2} S_{3}$ thin film supported on FTO were determined by XRD. Figure S1 shows a diffractogram where the peaks corresponding to the cubic phase of pure $\beta-\operatorname{In}_{2} S_{3}$ crystals appear. ${ }^{17,25}$ Vanadium doped and undoped layers did not show any changes of the cubic diffraction pattern. Only the particle sizes, obtained from the fullwidth-half-maxima values employing Scherrer's formula were different: the undoped $\beta-\operatorname{In}_{2} S_{3}$ layers exhibited an average grain size diameter of $12 \mathrm{~nm}$, and the V-doped films were evaluated at $8 \mathrm{~nm}$. These XRD show that the level of V doping studied in this work does not significantly alter the crystal structure, but does limits the crystal grain size in the films. No additional phase associated to $\mathrm{V}$ is observed in $\mathrm{V}$-doped XRD perhaps due to the low amount of $\mathrm{V}$, but its formation is not totally excluded (e.g. $\mathrm{V}_{2} \mathrm{~S}_{3}$ ). Comparing our results with previously reported Vdoped $\beta$ - $\operatorname{In}_{2} S_{3}$, where the crystal grains reached $20 \mathrm{~nm},{ }^{16}$ indicates that the synthetic strategy has an impact on the crystallite size in the final material.

Pure $\beta-\operatorname{In}_{2} S_{3}$ as well as $0.7 \%, 1.0 \%, 1.4 \%$ and $3.4 \%$ V-doped $\beta-\operatorname{In}_{2} S_{3}$, all deposited on FTO substrates, were analyzed by UV-Vis spectroscopy. 0.7-1.4 \% V-doped samples displayed a similar absorption behavior as a function of incident light energy to the pure $\beta$ - $\operatorname{In}_{2} S_{3}$ sample, but not the $3.4 \% \mathrm{~V}$-doped one. From the $(\alpha \mathrm{h} v)^{1 / \mathrm{m}}$ vs. hv representations an indirect band gap of 2.14 $\mathrm{eV}$ for 0.7-1.4\% V-doped and undoped $\beta$ - $\operatorname{In}_{2} \mathrm{~S}_{3}$ could be derived, as shown in Figure 1. A significant increase of the band gap energy is observed for $3.4 \% \mathrm{~V}$-doped $\beta$ - $\operatorname{In}_{2} S_{3}$, therefore it was not further characterized in detail.

Two different electron microscopy approaches were used on the samples: SEM-EDX was used for non-invasive morphology analysis and TEM-EDX was used to map the ions distribution along a sample particle (see Figure 2). The SEM images shown in figure 2A and $2 \mathrm{~B}$ reveal a flowerlike structure similar to that previously reported for $\beta-\operatorname{In}_{2} S_{3} \cdot{ }^{17}$ Figure 2A corresponds to pure and figure $2 \mathrm{~B}$ corresponds to $1 \% \mathrm{~V}$-doped $\beta-\mathrm{In}_{2} \mathrm{~S}_{3}$. The images show that the addition of $\mathrm{V}$ alters the nanostructure of the films, as the flakes and platelets are smaller and more strongly interconnected. This is consistent with the smaller grain sizes obtained by XRD analysis, providing further evidence that the addition of vanadium restricts the growth of the crystallite. 

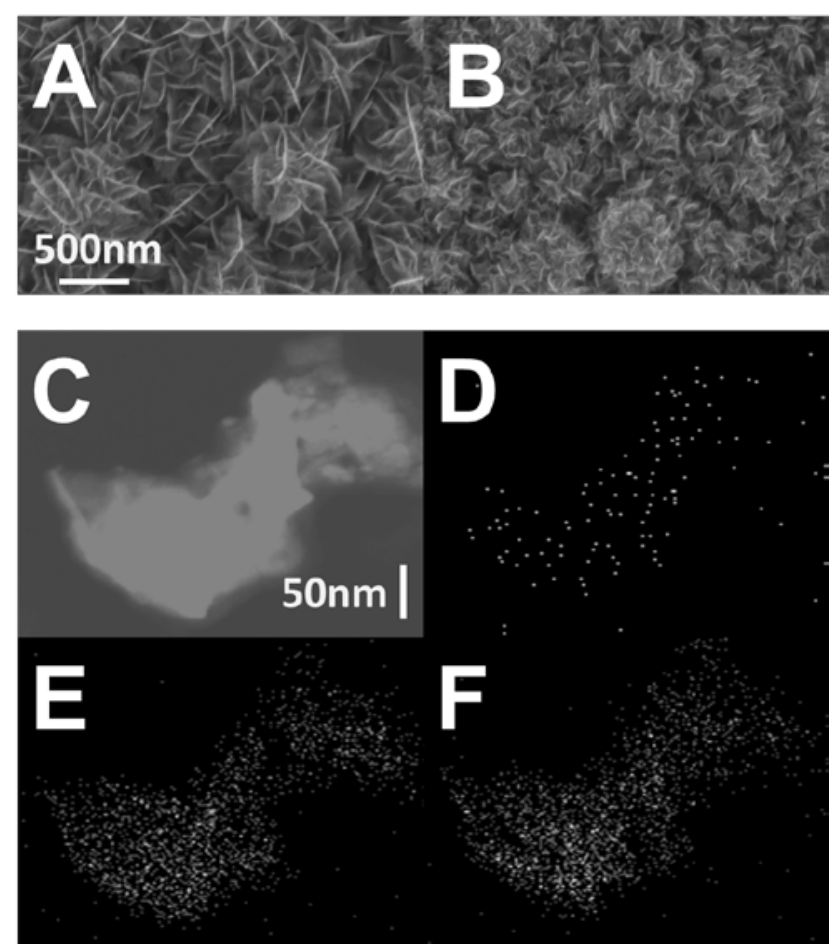

Figure 2. (A) SEM image of 3D intergrown $\beta$ - $\operatorname{In}_{2} \mathrm{~S}_{3}$ and (B) SEM image of 3D intergrown platelets of $1.4 \%$ V-doped $\beta$ - $\operatorname{In}_{2} \mathrm{~S}_{3}$ film particles. (C) Dark field STEM image showing a typical particle of $\beta-\operatorname{In}_{2} S_{3}$ doped with $1 \%$ Vanadium. (D, E, F) Mapping 2D spectra from the film particles in $C$ showing the $X$-ray emission of $V(D)$, In (E ) and $S(F)$, respectively.

Additional SEM images are available in the supplementary information (Figure S2). EDX analysis showed an In:S ratio of 2:2.5 for all of the samples, independent of the $\mathrm{V}$ content. No $\mathrm{V}$ was detected by EDX in the undoped $\beta$ - $\operatorname{In}_{2} S_{3}$ sample; however, it was detected in all V-doped samples. Figure S3 shows EDX typical results for $1 \% \mathrm{~V}$-doped $\operatorname{In}_{2}(\mathrm{~V}) \mathrm{S}_{3}$ sample, and its quantitative analysis is shown in Table S1. TEM images were recorded for $1 \% \mathrm{~V}$-doped $\beta$ - $\operatorname{In}_{2} \mathrm{~S}_{3}$ particles that were physically extracted from the FTO surface, dispersed in ethanol, and then deposited on a TEM grid. The technique known as scanning transmission electron microscopyhigh angle annular dark field (STEM-HAADF) was used to map a typical particle as observed by TEM, see Figure 2C. The spatial correlation obtained provided evidence of the V, In and $\mathrm{S}$ composition of the particle as shown in Figures 2 D, E, and F.

\section{X-ray Photoemission Spectroscopy (XPS) results}

Additional composition analysis of the $1.4 \%$ and the $3.4 \% \mathrm{~V}$-doped $\beta-\operatorname{In}_{2} \mathrm{~S}_{3}$ sample was performed by XPS (Figure S4), a technique that can provide information about bonding and oxidation state of elements close to the surface $(\approx 5 \mathrm{~nm})$ of material. For the $3.4 \% \mathrm{~V} \beta-\mathrm{In}_{2} \mathrm{~S}_{3}$ sample, the $\mathrm{V} \mathrm{2} \mathrm{p}_{3 / 2}$ peak is observed at $\sim 517.5 \mathrm{eV}$ (the $2 \mathrm{p}_{1 / 2}$ peak, broader and less intense, appears as expected at energy ca $7 \mathrm{~V}$ higher); a similar value seems to apply to the $1.4 \%$ sample. There are few literature references on the XPS binding energies of vanadium in a well-defined 
sulphide environment ${ }^{26}$. If we consider that $\mathrm{V}^{2+}$ in $\mathrm{V}_{2}\left(\mathrm{P}_{2} \mathrm{~S}_{6}\right)$ and $\mathrm{V}^{3+}$ in $\mathrm{V}_{1.5}\left(\mathrm{P}_{2} \mathrm{~S}_{6}\right)$ have been detected at respectively $514.2 \mathrm{eV}$ and $516.9 \mathrm{eV}^{27}$ and $\mathrm{V}^{4+}$ in $\left(\mathrm{NR}_{4}\right)_{2} \mathrm{~V}(\mathrm{dmit})_{3}$ has been detected at $523.3 \mathrm{eV}^{28}$, one could ascribe the here observed value to a $\mathrm{V}^{3+}$ state, i.e. an isovalent substitution as desired. In this context, the value $514.5 \mathrm{eV}$ reported for $\mathrm{V}^{4+}$ in $\mathrm{BaVS}_{3}{ }^{29}$ should probably be considered anomalous.

\section{Surface Photovoltage Spectroscopy (SPV) results}

Modulated SPV signals were obtained in-phase (X) and phase shifted by $90^{\circ}(\mathrm{Y})$ in relation to the reference signal. The amplitude of the SPV signal is given as the square root of the sum of the squares of the $X$ and $Y$ signals $\left.[19,20]:=\sqrt{\left(X^{2}\right.}+Y^{2}\right)$, while the so-called phase angles is given by: $\varnothing=\operatorname{arctn} \frac{X}{Y}$.

SPV results are shown in Figure 3. The sign of the in-phase SPV signals was positive for all $\beta$ $\mathrm{In}_{2} \mathrm{~S}_{3}$ thin films with and without $\mathrm{V}$ (Figure $3 \mathrm{~A}, \mathrm{~B}$ ), which means that the photo-generated electrons were preferentially migrating into the bulk of the film after excitation. Therefore the addition of vanadium to $\beta$ - $\operatorname{In}_{2} S_{3}$ did not change the n-type behavior of the semiconductor. The maximum of the in-phase SPV signal was reached at photon energies between 2.1 and $2.4 \mathrm{eV}$ for the pure $\beta-\mathrm{In}_{2} \mathrm{~S}_{3}$ layers; the thicknesses of which were varied from $350 \mathrm{~nm}$ to $970 \mathrm{~nm}$, and between 2.2 and $2.5 \mathrm{eV}$ for the $100 \mathrm{~nm}$ thick layer. A large decrease of the maximum of the inphase SPV signal from $35 \mu \mathrm{V}$ for bare $\beta-\operatorname{In}_{2} S_{3}$ to $11 \mu \mathrm{V}$ for $1.4 \% \mathrm{~V}$ is observed, while the position remained unchanged. The maximum in-phase SPV signal was reached at photon energies between 2.35 and $2.65 \mathrm{eV}$ for layers with $0.7 \% \mathrm{~V}$ and $1 \%$ vanadium, and with values of $8.5 \mu \mathrm{V}$ and $3.7 \mu \mathrm{V}$ respectively. The onset of the SPV signals of bare $\beta$ - $\operatorname{In}_{2} \mathrm{~S}_{3}$ layers was calculated by the initial change of the slope taken from the SPV amplitude plot in logarithmic scale as shown in Figure 3C, 3D. The onset was at $0.95 \mathrm{eV}$ for 970 to $350 \mathrm{~nm}$ layers, and shifted to $1.05 \mathrm{eV}$ for $100 \mathrm{~nm}$ layer. These results are in accordance to those reported previously for bare $\beta$-In ${ }_{2} S_{3}$ varying the thickness, ${ }^{21}$ in which thinner layers had higher onset SPV signals. For V doped samples (Fig 3.D) two exponential tails below the band gap were observed. The values for the first onset SPV signal was at $0.9 \mathrm{eV}$ for the $0.7 \% \mathrm{~V}$ sample, at $0.95 \mathrm{eV}$ for $1 \% \mathrm{~V}$ and at 0.8 $\mathrm{eV}$ for $1.4 \% \mathrm{~V}$. The second onset value was at $1.55 \mathrm{eV}$ for the $0.7 \% \mathrm{~V}$ sample, at $1.6 \mathrm{eV}$ for 1 $\% \mathrm{~V}$, and at $1.25 \mathrm{eV}$ for $1.4 \% \mathrm{~V}$. These two exponential tails may be due to disordered or deep defects states added by the presence of vanadium, contributing to the SPV amplitude and caused by a decrease of disorder. The addition of these defect states in the matrix causes the formation of an in-gap level in between the conduction and valence band. 

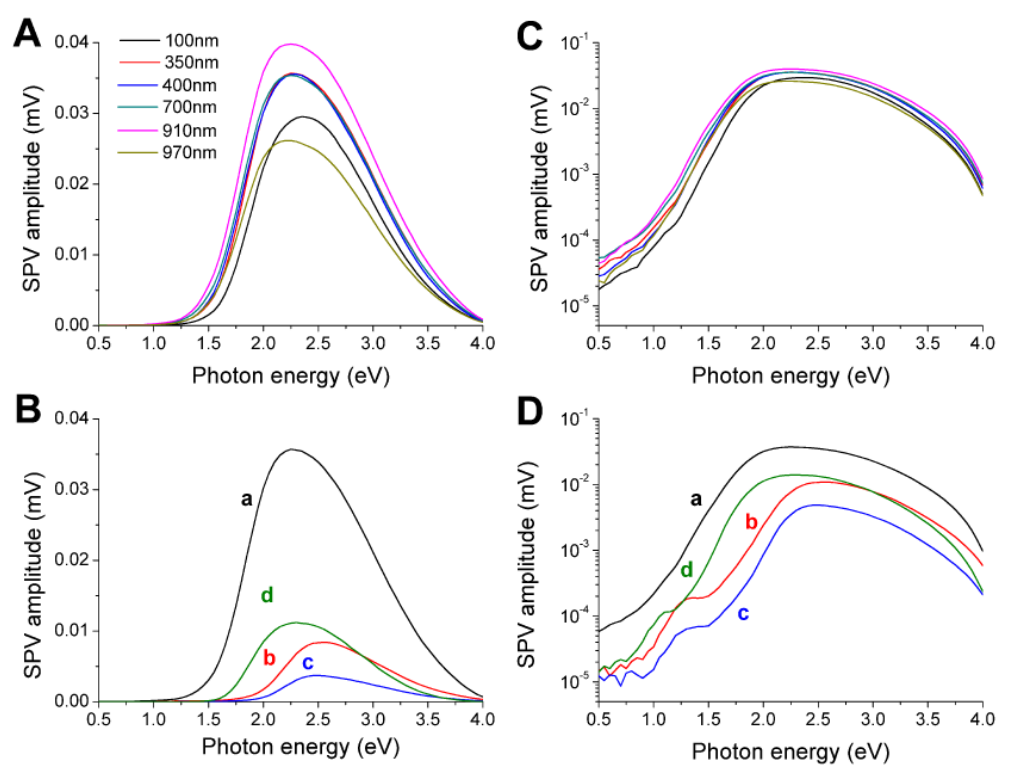

Figure 3. SPV signals of a pure $\beta$ - $\operatorname{In}_{2} S_{3}$ and V-doped $\beta$ - $\operatorname{In}_{2} S_{3}$ thin films deposited on FTO. The SPV amplitude (A, B), and SPV amplitude plotted in logarithmic scale (C, D) versus the photon energy for $\beta-\operatorname{In}_{2} S_{3}$ layers of different film thickness as indicate in the figure legend $(A, C)$ and for $\beta$ - $\mathrm{In}_{2} \mathrm{~S}_{3}$ layers of approximately 350nm thickness doped with $0 \% \mathrm{~V}$ (a), $0.7 \% \mathrm{~V}$ (b), $1 \% \mathrm{~V}$ (c) and $1.4 \% \mathrm{~V}(\mathrm{~d})(\mathrm{B}, \mathrm{D})$.

The phase angle contains information about the direction of charge separation and about the time response of the SPV signal with respect to the modulation period. The phase angles change to $90^{\circ}$ if the time responses of the SPV signals are much slower than the modulation period for preferential separation of photo-generated electrons towards the internal contact. Phase angles between -90 and $0^{\circ}$ correspond to preferentially modulated separation of photon-generated electrons towards the bulk. As shown in Figure 4A for the layers without vanadium, the phase angle changed from $-50^{\circ}$ at photon energies below $1.5 \mathrm{eV}$ to $-16^{\circ}$ at photon energies between 2.1 and 2.6eV, and decreased again with further increasing of the photon energy. This means that the modulated response was much slower for the deep defects states. The values of phase angle were similar for all layer thicknesses studied in the report. However, as shown in Figure 4B, for $\beta$ $\mathrm{In}_{2} \mathrm{~S}_{3}$ doped with $0.7 \% \mathrm{~V}$ and $1 \% \mathrm{~V}$ no significant change in the phase angle varying the photon energy from 1.3 to $4 \mathrm{eV}$ was observed, remaining at around $-45^{\circ}$. For the $1.4 \% \mathrm{~V}$-doped layer, the phase angle changed from $-80^{\circ}$ at photon energies below $1.5 \mathrm{eV}$ to $-40^{\circ}$ at photon energies between 2.1 and $2.6 \mathrm{eV}$, and decreased again with further increasing photon energy. Thus, it showed behavior similar to the undoped $\beta-\operatorname{In}_{2} S_{3}$ layer. 

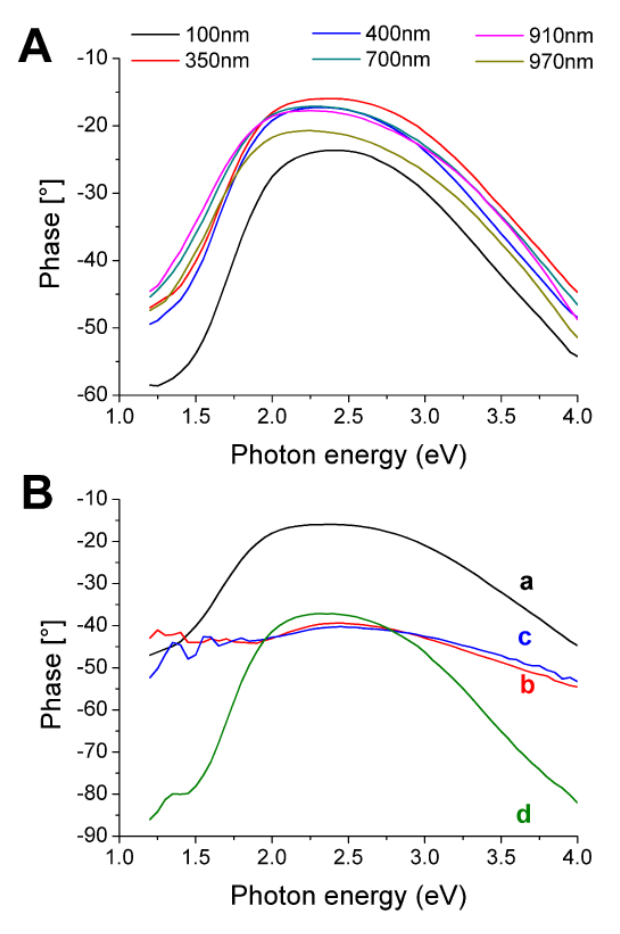

Figure 4. Phase angles of $\beta$ - $\operatorname{In}_{2} S_{3}$ and V-doped $\beta$ - $\operatorname{In}_{2} S_{3}$ thin films on FTO versus photon energy. (A) $\beta-\operatorname{In}_{2} S_{3}$ films of different thicknesses as indicated in the figure legend. (B) $\beta$ - $\operatorname{In}_{2} \mathrm{~S}_{3}$ films doped with $0 \% \mathrm{~V}(\mathrm{a}), 0.7 \% \mathrm{~V}$ (b), 1\%V (c) and 1.4\%V (d) (thin films thickness $350 \mathrm{~nm}$ ).

Time-resolved microwave conductivity results

TMRC is a technique based on the measurement of the change in the reflected microwave power from the analyzed semiconductor layer after its irradiation with a nanosecond laser pulse that generates electron-hole pairs. This technique was applied to investigate pure and V-doped $\beta$ $\mathrm{In}_{2} \mathrm{~S}_{3}$ thin films deposited on quartz substrates by the spray ILGAR method using 15 deposition cycles.

The signals obtained by TRMC for vanadium free and vanadium doped $\beta-\operatorname{In}_{2} S_{3}$ thin films using $532 \mathrm{~nm}$ excitation of $3.89 \times 10^{11}$ photons pulse $\mathrm{cm}^{-2}$ are shown in Figure 5A. The photon energy used was above the bandgap energy of $\beta-\operatorname{In}_{2} S_{3}$, so the optical excitation was high enough to form free electrons and holes in the conduction and valence bands, respectively. The minimum mobility of generated carriers was obtained from the peak of the measured signal (maximum $\varphi \Sigma \mu$ ), and the lifetime of excited charge carriers was deduced from the decay of signal. ${ }^{30}$ The measurements revealed a carrier mobility value for bare $\beta-\operatorname{In}_{2} S_{3}$ that was in the same range as other metals used for photoelectrodes like metal oxides semiconductors, e.g. $\mathrm{Cu}_{2} \mathrm{O}, \mathrm{WO}_{3}$, $\mathrm{BiVO}_{4}$ (see Table 2). ${ }^{24}$ However, for the $0.7 \%$, $1 \%$ and $1.4 \%$ vanadium doped layers the values were one order of magnitude lower. 

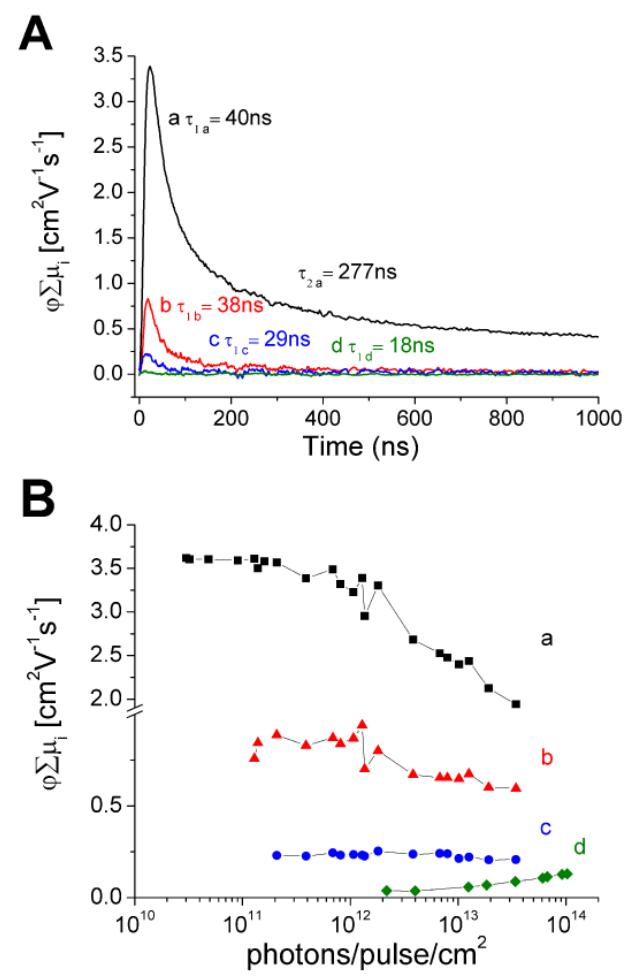

Figure 5. TRMC signals recorded for pure (a), 0.7\% V-doped (b), 1\% V-doped (c) and 1.4\% Vdoped $\beta$ - $\operatorname{In}_{2} S_{3}$ versus Time (A) and versus excitation intensity (B).

The microwave conductance transient changed upon doping the $\beta$ - $\operatorname{In}_{2} S_{3}$ thin layer with vanadium. At a laser pulse intensity of $3.89 \times 10^{11}$ photons $/$ pulse $/ \mathrm{cm}^{2}$ the maximum $\varphi \Sigma \mu$ for $0.7 \% \mathrm{~V}$ was $0.9 \mathrm{~cm}^{2} \mathrm{~V}^{-1} \mathrm{~s}^{-1}$, only 4 times lower than that of the pure material. However, a higher decrease was observed for $1 \% \mathrm{~V} \beta$ - $\mathrm{In}_{2} \mathrm{~S}_{3}$ resulting in a value of maximum $\varphi \Sigma \mu$ of $0.2 \mathrm{~cm}^{2} \mathrm{~V}^{-1} \mathrm{~s}^{-}$ 1 , which is 18 times lower. Sample doped with $1.4 \% \mathrm{~V}$ showed even smaller maximun $\varphi \Sigma \mu$ of $0.04 \mathrm{~cm}^{2} \mathrm{~V}^{-1} \mathrm{~s}^{-1}$ at a laser pulse intesity $2.18 \times 10^{12}$ photons $/$ pulse $/ \mathrm{cm}^{2}$. The lifetime of the carriers was calculated from the constant of the exponential function used for the fitting. For pure films the fitting required two constants, which translated into two carrier lifetimes: one of 40ns and another one that lasts longer (277ns). However, for $\mathrm{V}$-doped $\beta$ - $\operatorname{In}_{2} S_{3}$ thin films only one constant was obtained, indicating charge carrier lifetimes of $38 \mathrm{~ns}$ for $0.7 \% \mathrm{~V}, 29 \mathrm{~ns}$ for $1 \% \mathrm{~V}$ and $18 \mathrm{~ns}$ for $1.4 \% \mathrm{~V}$. Although the lifetimes are lower for the $\mathrm{V}$ doped films compared to the pure $\beta-\operatorname{In}_{2} S_{3}$, they still are high compared to metal oxide semiconductors. ${ }^{14}$ The diffusion length decreases strongly from $619 \mathrm{~nm}$ for the pure material to $343 \mathrm{~nm}$ in the case $0.7 \% \mathrm{~V}$ doped, $150 \mathrm{~nm}$ on $1 \% \mathrm{~V}$ and $43 \mathrm{~nm}$ on $1.4 \% \mathrm{~V}$ doped $\beta-\mathrm{In}_{2} \mathrm{~S}_{3}$ (Table 1). Other oxides values are shown in Table 2 . The decrease of maximum $\varphi \Sigma \mu$ must be due to an increase of defects in the matrix explained by the formation of an in-gap level that contributes to the recombination and trapping of the charge carriers. The increased doping is not leading to a further lowering of the mobility but evoking a shorter life time of excited charge carriers. The mobility as a function of excitation intensity, showed in Figure 5B, is leading to an increase of the mobility of pure samples. This behavior is explained by assuming a high defect density in the pure material. With increasing light intensity the trap states of the defects in the band are filled leading to a smaller effective mobility. This behavior could not be found in V-doped layers. 
Table 1: Carrier mobility, carrier lifetime and diffusion Length values.

\begin{tabular}{|c|c|c|c|c|c|c|}
\hline$\beta-\operatorname{In}_{2} S_{3}$ & Carrier mobility $\mu$ & $\left.m^{2} V^{-1} s^{-1}\right)$ & & & $\begin{array}{l}\text { Diff } \\
L_{D}(\end{array}$ & Length \\
\hline $\begin{array}{ll}\beta-\operatorname{In}_{2} S_{3} & \text { film } \\
\text { type } & \end{array}$ & $\begin{array}{l}@ 3.89 \times 10^{11} \text { photo } \\
\mathrm{ns} / \mathrm{cm}^{2} / \text { pulse }\end{array}$ & $\begin{array}{l}@ 10^{9} \\
\text { photons/cm²/pulse } \\
\text { (extrapolated) }\end{array}$ & $T_{1}$ & $T_{2}$ & $\mathrm{~L}_{\mathrm{D} 1}$ & $\mathrm{~L}_{\mathrm{D} 2}$ \\
\hline $0 \% \mathrm{~V}$ & 3.6 & 3.7 & 40 & 277 & 619 & 1630 \\
\hline $0.7 \% \mathrm{~V}$ & 0.9 & 1.2 & 38 & - & 343 & - \\
\hline $1 \% \mathrm{~V}$ & 0.2 & 0.3 & 29 & - & 150 & - \\
\hline $1.4 \% \mathrm{~V}$ & $\begin{array}{l}0.04 @ 2.18 x 10^{12} \\
\text { photons/cm²/pulse }\end{array}$ & - & 18 & - & 43 & - \\
\hline
\end{tabular}

Table 2: Carrier Mobility, Lifetime, and Diffusion Length of Several Metal Oxides

\begin{tabular}{|l|l|l|l|}
\hline Material & $\begin{array}{l}\text { Carrier } \\
\text { mobility } \mu \\
\left(\mathrm{cm}^{2} \mathrm{~V}^{-1} \mathrm{~s}^{-1}\right)\end{array}$ & $\begin{array}{l}\text { Carrier } \\
\text { lifetime T }\end{array}$ & $\begin{array}{l}\text { Diffusion } \\
\text { Length L } \\
(\mathrm{nm})\end{array}$ \\
\hline $\mathrm{Fe}_{2} \mathrm{O}_{3}$ & 0.5 & $3 \mathrm{ps}$ & $2-4$ \\
\hline $\mathrm{WO}_{3}$ & 10 & $1-9 \mathrm{~ns}$ & $150-500$ \\
\hline $\mathrm{Cu}_{2} \mathrm{O}$ & 6 & $147 \mathrm{ps}$ & 25 \\
\hline $\mathrm{BiVO}_{4}$ & 0.044 & $40 \mathrm{~ns}$ & 70 \\
\hline
\end{tabular}

\section{Photoluminescence measurements}

The Photoluminescence (PL) of $\beta$ - $\operatorname{In}_{2} S_{3}$ and V-doped $\beta$ - $\operatorname{In}_{2} S_{3}$ samples show a broad defect related emission peaked near $1.35 \mathrm{eV}$ at $30 \mathrm{~K}$ (Figure 6A). It can be seen in Figure 6A that PL yield drops by factor of 3, while the full width at half maximum (FWHM) and the PL maximum position remain almost unaffected by the $\mathrm{V}$-doping. This implies that the effect of the $\mathrm{V}$ defect level cannot account for the dominant radiative recombination channel in $\beta-\operatorname{In}_{2} S_{3}$ samples. The previous studies suggested that donor-acceptor transitions involving $\mathrm{V}_{\mathrm{S}}(\mathrm{donor})$ and $\mathrm{V}_{\text {In }}$ (acceptor) can be responsible for the broad defect PL band at $1.5 \mathrm{eV}$ in the $\beta$ - $\mathrm{In}_{2} \mathrm{~S}_{3}$ single crystals. ${ }^{31,32}$ Although in earlier work by Nakanishi et $a l^{33}$ a broad defect band at 1.4.eV in the $\beta$ $\mathrm{In}_{2} \mathrm{~S}_{3}$ single crystals was revealed, the origin of the radiative transition has not been discussed. Based on these earlier interpretations it seems reasonable to assume that the observed defect PL band in $\beta-\operatorname{In}_{2} S_{3}$ samples is due to $S$ and In vacancies in the host lattice. 

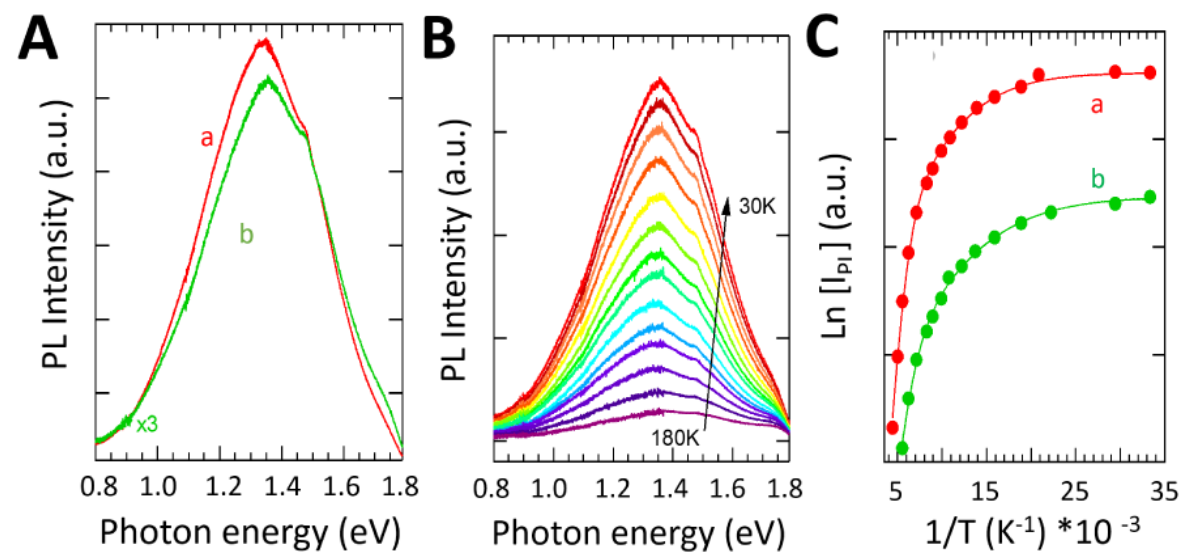

Figure 6. (a) Photoluminescence spectra of the doped (green) and pure (red) $\beta$-In ${ }_{2} S_{3}$ layer of $700 \mathrm{~nm}$ thickness layers recorded at $30 \mathrm{~K}$. (b) Temperature dependent PL of the V-doped $\beta$ $\mathrm{In}_{2} \mathrm{~S}_{3}$ layer (c) the temperature dependence of the PL intensity of the V-doped (green) and pure (red) $\beta-\operatorname{In}_{2} S_{3}$ layer.

In an attempt to further analyze PL properties and a V-doping effect, temperature dependent PL measurements have been conducted. As can be noticed in Figure 6B the PL signal is reduced by one order of magnitude and it is completely quenched for the $\mathrm{T}>200 \mathrm{~K}$ in the $\beta-\mathrm{In}_{2} \mathrm{~S}_{3}: \mathrm{V}$ sample as well as in the pure $\beta$ - $\operatorname{In}_{2} S_{3}$ one (not shown here). For the both samples the defect related PL band is shifted to the low energy by about $20 \mathrm{meV}$ and broadened by $70 \mathrm{meV}$ over the measured temperature range 30-180K. Figure 6C shows the Arrhenius plots of the integrated PL intensity, $\mathrm{I}_{\mathrm{PL}}$, as a function of the temperature. The solid lines are the least -squares linear fits to the PL intensity quenching model with two competitive recombination channels ${ }^{34}$ as $I_{P L}=I_{0} /\left(1+a_{1} \exp (-\right.$ $\left.E_{A 1} / k T\right)+a_{2} \exp \left(-E_{A 2} / k T\right)$, where $I_{0}$ is the intensity at the lowest temperature, $a_{1}$ and $a_{2}$ are the rate parameters of the non-radiative process with activation energies $E_{A 1}$ (for $\mathrm{T}<100 \mathrm{~K}$ ) and $E_{A 2}$ (for $\mathrm{T}>100 \mathrm{~K})$. We obtained $E_{A 1} \approx 19(16) \mathrm{meV}$ and $E_{A 2} \approx 100(80) \mathrm{meV}$ for the $\beta-\operatorname{In}_{2} S_{3}(\beta$ $\left.\mathrm{In}_{2} \mathrm{~S}_{3}: \mathrm{V}\right)$, samples respectively. The determined $E_{A 2}$ value is in agreement with reported $105 \mathrm{meV}$ activation energy of the defect band at $1.5 \mathrm{eV}$ in the $\beta-\mathrm{In}_{2} \mathrm{~S}_{3}$ single crystals. ${ }^{31}$ According to Ho, ${ }^{30}$ the $105 \mathrm{meV}$ energy corresponds to the depth of the $\mathrm{V}_{\text {In }}$ acceptor level. In the present study by comparing $\beta-\mathrm{In}_{2} \mathrm{~S}_{3}$ with $\beta$ - $\mathrm{In}_{2} \mathrm{~S}_{3}: \mathrm{V}$ sample we observe change of $20 \mathrm{meV}$ in $E_{A 2}$ value, which might be attributed to the V-doping effect. The lower $E_{A 1}$ energy could not be compared with earlier reports as low temperature analysis has not been done, but we note that PL quenching has been observed, too. ${ }^{31}$

\section{Electrochemical measurements: Flat band potential/Photocurrent/ICPE results}

To determine the flat-band potentials of the films, electrochemical impedance spectroscopy (EIS) measurements were performed and the Mott-Schottky equation was applied, which relates semiconductor-electrolyte capacitance values to applied potential. During EIS measurements the applied potential which was varied in the range from $-0.4 \mathrm{~V}$ to $-0.95 \mathrm{~V}$ vs RHE, in a buffer solution at a frequency of $500 \mathrm{~Hz}$. Figure 7 shows the Mott-Schottky plot of pure $\beta$ - $\operatorname{In}_{2} \mathrm{~S}_{3}, 0.7 \%$ $\mathrm{V} \beta-\mathrm{In}_{2} \mathrm{~S}_{3}, 1 \% \mathrm{~V} \beta-\mathrm{In}_{2} \mathrm{~S}_{3}$ and $1.4 \% \mathrm{~V} \beta-\mathrm{In}_{2} \mathrm{~S}_{3}$, respectively. A clear shift of at least $+0.2 \mathrm{~V}$ of the flat-band potential was measured after doping the $\beta$ - $\operatorname{In}_{2} S_{3}$ layers with vanadium. It changed from $-0.92 \mathrm{~V}$ vs RHE in the case of pure $\beta-\operatorname{In}_{2} S_{3}$ to $-0.70 \mathrm{~V},-0.68 \mathrm{~V}$ and $-0.72 \mathrm{~V}$ for $0.7 \% \mathrm{~V} \beta$ $\mathrm{In}_{2} \mathrm{~S}_{3}, 1 \% \mathrm{~V} \beta$-In $\mathrm{In}_{2} \mathrm{~S}_{3}$ and $1.4 \% \mathrm{~V} \beta$ - $\operatorname{In}_{2} \mathrm{~S}_{3}$ layers, respectively. These shifts in the flat-band 
potential suggest that the formation of the in-gap level does shift the valence band and conductive band to more positive potentials, situation illustrated in Figure 8.

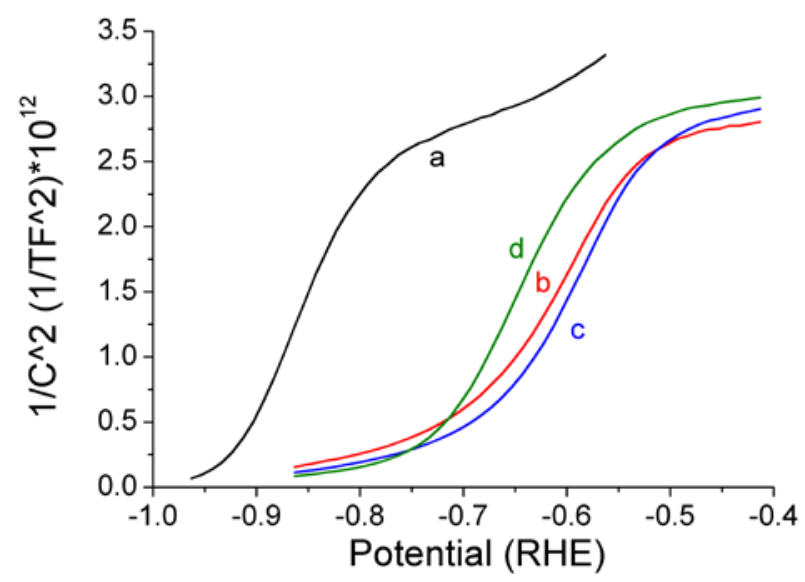

Figure 7. Mott-Schottky plot for $\beta$ - $\operatorname{In}_{2} S_{3}, 0.7 \% \mathrm{~V} \beta$ - $\operatorname{In}_{2} S_{3}, 1 \% \mathrm{~V} \beta$ - $\operatorname{In}_{2} S_{3}$ and $1.4 \% \mathrm{~V} \beta$ - $\operatorname{In}_{2} S_{3}$. The interception of the tangent with the $\mathrm{x}$-axis determines the flat-band potential value for each sample.

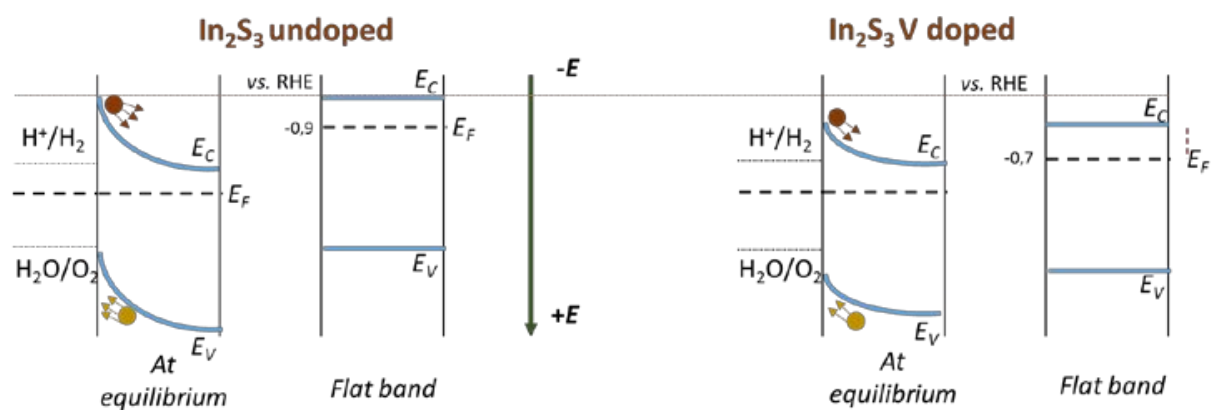

Figure 8. Schematic position of the Fermi Level in pure and V-doped $\beta$ - $\operatorname{In}_{2} S_{3}$ thin films. 

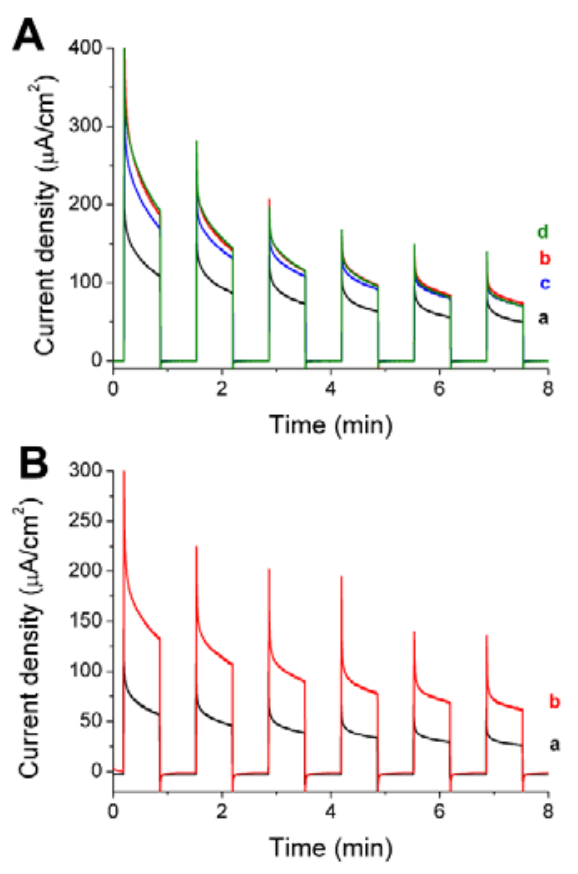

Figure 9. (A) Photocurrents for $\beta-\operatorname{In}_{2} S_{3}(a), \beta-\operatorname{In}_{2} S_{3} 0.7 \% V$ (b), $\beta-\operatorname{In}_{2} S_{3} 1 \% V$ (c) and $\beta-\operatorname{In}_{2} S_{3}$ $1.4 \% \mathrm{~V}(\mathrm{~d})$ at a potential of $-0.1 \mathrm{~V}$ vs SHE, using a solar simulator (AM 1.5). (B) Photocurrents for $\beta-\operatorname{In}_{2} S_{3}(a)$ and $\beta-\operatorname{In}_{2} S_{3} 1$.

Unfortunately, $\beta$ - $\operatorname{In}_{2} S_{3}$ thin films on FTO are electrochemically only stable in the potential range from $-1.0 \mathrm{~V}$ and $-0.40 \mathrm{~V}$ vs RHE. In Figure 9A, the photocurrent response of $\beta-\mathrm{In}_{2} \mathrm{~S}_{3}$ with and without vanadium vs time under solar simulator conditions, applying a constant potential of -0.3 $\mathrm{V}$ vs RHE, are shown. Processes of recombination were observed in all samples, which were not affected by vanadium doping. The decrease in photocurrent with time can presumably be correlated to the corrosion of the material. In all the V-doped samples the photocurrent was higher than in pure $\beta$ - $\operatorname{In}_{2} S_{3}$ with no significant difference among the doped samples. To reduce the corrosion processes at the $\beta-\operatorname{In}_{2} S_{3}$ electrode surface in contact with the electrolyte, a thin layer of $\mathrm{Cr}(4 \mathrm{~nm})$ and afterwards of $\mathrm{Au}(200 \mathrm{~nm})$ were deposited consecutively by evaporation onto the $\beta-\operatorname{In}_{2} S_{3}$ thin films. Figure 9B shows the photocurrent of the samples covered with gold. Less corrosion was observed in both pure and V-doped thin layers, but also smaller photocurrents were measured due to slower diffusion of the holes to the surface. In any case, it is confirmed that the photocurrents are clearly higher for the V-doped samples up to $1.4 \% \mathrm{~V}$, but for the $3.4 \% \mathrm{~V}$ sample the photocurrent decreases (Figure S5), as expected from its higher indirect band gap.

ICPE measurements were performed with a $300 \mathrm{~W}$ power lamp filtered to lower intensity for specific wavelengths and measured in order to normalize the results. The lowest values were measured for the $1 \% \mathrm{~V}$ doped sample. In fact, the $1 \% \mathrm{~V} \beta-\operatorname{In}_{2} \mathrm{~S}_{3}$ sample was the one that showed the strongest differences in all the techniques compared to $\beta-\operatorname{In}_{2} S_{3}$ thin films. The ICPE of all the V-doped samples decreased strongly compared to pure $\beta-\operatorname{In}_{2} S_{3}$. One possible reason for this contrasting behavior may be the much lower light intensity used in the wavelength-resolved experiments of Figure 10. If the in-gap levels are partially filled (which is the desired situation for the operation of the intermediate band principle), each one of the two photon absorption 
events (producing the valence band to in-gap level, and in-gap level to conduction band electron excitations) does not depend on the occurrence of the other one to take place; but if the in-gap level is empty the second event can only occur with high probability if the first one has previously taken place (and a similar argument applies if the level is full), so that the whole twophoton process will depend quadratically on the incident light intensity. For low light intensities the two-photon process will not be significant, and the behavior will be more dominated by recombination effects, especially if these are not quenched by a delocalized character of the ingap level.

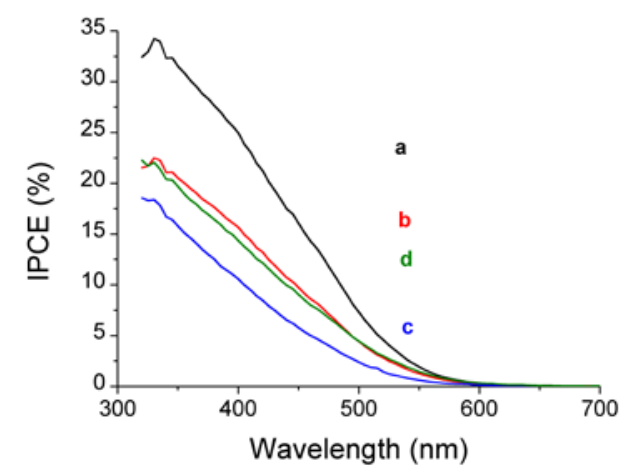

Figure 10. IPCE (\%) of $\beta-\operatorname{In}_{2} S_{3}(a), \beta-\operatorname{In}_{2} S_{3} 0.7 \% \mathrm{~V}(\mathrm{~b}), \beta-\operatorname{In}_{2} S_{3} 1 \% \mathrm{~V}$ (c) and $\beta-\operatorname{In}_{2} S_{3} 1.4 \% \mathrm{~V}$ (d) under an applied potential of $-0.1 \mathrm{~V}$ vs SHE.

\section{CONCLUSIONS}

Structural, morphological, or surface-chemical explanations for the decrease in maximum $\varphi \Sigma \mu$ are not very likely, since no significant differences in the X-Ray diffractograms, UV-Vis absorption spectra, scanning electron micrographs, or X-Ray photoemission spectra were observed between the bare and V-doped $\beta$ - $\operatorname{In}_{2} S_{3}$ thin films. Therefore, the decrease of carrier lifetime and diffusion length calculated from TMRC measurements suggests the formation of an in-gap level which contributes to the recombination and trapping of the charge carriers in $\mathrm{V}$ doped $\beta-\operatorname{In}_{2} S_{3}$ thin films. These results correlates with SPV results, where a different process for charge separation was observed for $\beta-\mathrm{In}_{2} \mathrm{~S}_{3}$ layers doped with $\mathrm{V}$, suggesting again the formation of an in-gap level.

Several techniques had been performed to study the photocurrent properties and flat band potential for $\beta$ - $\operatorname{In}_{2} S_{3}$ and $V$ doped $\beta$ - $\operatorname{In}_{2} S_{3}$ thin films. The shift on the flat band potential for the V-doped samples can be explained by a concentration of defects above the valence band that shifts the level of the valence and conduction bands to more positive potentials, increasing lightly the overpotential for electrolyte oxidation. The IPCE measurements suggest that the formation of the in-gap level increases the charge trapping. 
Supporting Information. Experimental results containing XRD, SEM, TEM, EDX, XPS analyses and photocurrent response are provided as Supporting Information. This material is available free of charge via the Internet at http://pubs.acs.org.

\section{AUTHOR INFORMATION}

Corresponding Author

* Marcos Pita, Ph.D. E-mail: marcospita@icp.csic.es

Instituto de Catálisis y Petroleoquímica, CSIC

C/ Marie Curie, 2. L10 28049 Madrid, Spain

\section{ACKNOWLEDGMENT}

The authors thank the Spanish MINECO projects CTQ2012-32448 and CTQ2015-71290-R. CT thanks the Spanish MINECO for her BES-2013-064099 contract and EEBB-I-16-11240 grant.

\section{REFERENCES}

(1) Rehman, S.; Ullah, R.; Butt, A. M.; Gohar, N. D. Strategies of making $\mathrm{TiO}_{2}$ and $\mathrm{ZnO}$ visible light active. J. Hazard. Mater. 2009, 170, 560-569.

(2) Yin, W.-J.; Tang, H.; Wei, S.-H.; Al-Jassim, M. M.; Turner, J.; Yan, Y. Band structure engineering of semiconductors for enhanced photoelectrochemical water splitting: the case of $\mathrm{TiO}_{2 .}$. Physical Review B 2010, 82, 045106.

(3) Tong, H.; Ouyang, S.; Bi, Y.; Umezawa, N.; Oshikiri, M.; Ye, J. Nano-photocatalytic Materials: Possibilities and Challenges. Advanced Materials 2012, 24, 229-251.

(4) Luque, A.; Martí, A. Increasing the efficiency of ideal solar cells by photon induced transitions at intermediate levels. Phys. Rev. Lett. 1997, 78, 5014-5017.

(5) Luque, A.; Martí, A. A metallic intermediate band high efficiency solar cell. Prog. Photovoltaics 2001, 9, 73-86.

(6) Wolf, M. Limitations and possibilities for improvement of photovoltaic solar energy converters: part I: considerations for earth's surface operation. Proc. IRE, 1960, 48, 1246-1263.

(7) Palacios, P.; Fernández, J. J.; Sánchez, K.; Conesa, J. C.; Wahnón, P. First-principles investigation of isolated band formation in half-metallic Ti x Ga 1- x P (x=0.3125-0.25) Phys. Rev. B: Condens. Matter Mater. Phys. 2006, 73, 085206.

(8) Palacios, P.; Sánchez, K.; Conesa, J. C.; Fernández, J. J.; Wahnón, P. Theoretical modelling of intermediate band solar cell materials based on metal-doped chalcopyrite compounds. Thin Solid Films 2007, 515, 6280-6284.

(9) Wahnón, P.; Conesa, J. C.; Palacios, P.; Lucena, R.; Aguilera, I.; Seminovski, Y.; Fresno, F. $\mathrm{V}$-doped $\mathrm{SnS}_{2}$ : a new intermediate band material for a better use of the solar spectrum. Phys. Chem. Chem. Phys. 2011, 13, 20401-20407. 
(10) Palacios, P.; Aguilera, I.; Sánchez, K.; Conesa, J. C.; Wahnón, P. Transition-metalsubstituted indium thiospinels as novel intermediate-band materials: prediction and understanding of their electronic properties. Phys. Rev. Lett. 2008, 101, 046403.

(11) Yu, K. M.; Walukiewicz, W.; Wu, J.; Shan, W.; Beeman, J. W.; Scarpulla, M. A.; Dubon, O. D.; Becla, P. Synthesis and optical properties of II-O-VI highly mismatched alloys. J. Appl. Phys. 2004, 95, 6232-6238.

(12) Yu, K. M.; Walukiewicz, W.; Ager, J. W.; Bour, D.; Farshchi, R.; Dubon, O. D.; Li, S. X.; Sharp, I. D.; Haller, E. E. Multiband GaNAsP quaternary alloys. Appl. Phys. Lett. 2006, 88, 092110.

(13) Lucena, R.; Aguilera, I.; Palacios, P.; Wahnón, P.; Conesa, J. C. Synthesis and spectral properties of nanocrystalline $\mathrm{V}$-substituted $\operatorname{In}_{2} \mathrm{~S}_{3}$, a novel material for more efficient use of solar radiation. Chem. Maters. 2008, 20, 5125-5127.

(14) Dalas, E.; Sakkopoulos, S.; Virtoratos, E.; Maroulis, G.; Kobotiatis, L. Aqueous precipitation and electrical properties of In2S3: characterization of the $\operatorname{~nn}_{2} \mathrm{~S}_{3}$ /polyaniline and $\mathrm{In}_{2} \mathrm{~S}_{3}$ /polypyrrole heterojunctions. J. Mater. Sci. 1993, 28, 5456-5460.

(15) Asikainen, T.; Ritala, M.; Leskelä, M. Growth of $\operatorname{In}_{2} S_{3}$ thin films by atomic layer epitaxy. Applied Surface Science, 1994, 82-83, 122-125.

(16) Kim, W. T.; Kim, C. D. Optical energy gaps of $\beta$ - $\operatorname{In}_{2} S_{3}$ thin films grown by spray pyrolysis. J. Appl. Phys. 1986, 60, 2631-2633.

(17) Chen, L.-Y.; Zhang, Z.-D.; Wang, W.-Z. Self-assembled porous $3 \mathrm{D}$ flowerlike $\beta-\mathrm{In}_{2} \mathrm{~S}_{3}$ structures: synthesis, characterization, and optical properties. J. Phys. Chem. C 2008, 112, 41174123.

(18) Lucena, R.; Conesa, J. C.; Aguilera, I.; Palacios, P.; Wahnón, P. V-substituted $\operatorname{In}_{2} \mathrm{~S}_{3}$ : an intermediate band material with photocatalytic activity in the whole visible light range. J. Mater. Chem. A 2014, 2, 8236-8245.

(19) Allsop, N. A.; Schönmann, A.; Belaidi, A.; Muffler, H.-J.; Mertesacker, B.; Bohne, W.; Strub, E.; Röhrich, J.; Lux-Steiner, M.C.; Fischer, Ch.-H. Indium sulfide thin films deposited by the spray ion layer gas reaction technique. Thin Solid Films 2006, 513, 52-56.

(20) Juma, A. O.; Azarpira, A.; Steigert, A.; Pomaska, M.; Fischer, C.-H.; Lauermann, I.; Dittrich, T. Role of chlorine in $\mathrm{In}_{2} \mathrm{~S}_{3}$ for band alignment at nanoporous- $\mathrm{TiO}_{2} / \mathrm{In}_{2} \mathrm{~S}_{3}$ Interfaces. $J$. Appl. Phys. 2013, 114, 053711.

(21) Juma, A.; Kavalakkatt, J.; Pistor, P.; Latzel, B.; Schwarzburg, K.; Dittrich, T. Formation of a disorderd hetero-junction by diffusion of CuI from CuSCN into $\operatorname{In}_{2} \mathrm{~S}_{3}$ layers: a surface photovoltage study. Phys. Status Solidi A 2012, 209, 663-668.

(22) Duzhko, V.; Timoshenko, V. Yu.; Koch, F.; Dittrich, T. Photovoltage in nanocrystalline porous $\mathrm{TiO}_{2}$. Phys. Rev. B 2001, 64, 075204. 
(23) Kroeze, J. E.; Savenije, T. J.; Warman, J. M. Electrodeless determination of the trap density, decay kinetics, and charge separation efficiency of dye-sensitized nanocrystalline $\mathrm{TiO}_{2} . J . \mathrm{Am}$. Chem. Soc. 2004, 126, 7608-7618.

(24) Abdi, F. F.; Savenije, T. J.; May, M. M.; Dam, B.; van de Krol, R. The origin of slow carrier transport in $\mathrm{BiVO}_{4}$ thin film photoanodes: A time-resolved microwave conductivity Study. $J$. Phys. Chem. Lett. 2013, 4, 2752-2757.

(25) Fu, X.; Wang, X.; Chen, Z.; Zhang, Z.; Li, Z.; Leung, D. Y.C.; Wu, L.; Fu, X. Photocatalytic performance of tetragonal and cubic $\beta-\operatorname{In}_{2} S_{3}$ for the water splitting under visible light irradiation. Applied Catalysis B: Environmental 2010, 95, 393-399.

(26) Soria, J.; Conesa, J. C.; Granados, M. L.; Mariscal, R.; Fierro, J. L. G.; de la Banda, J. F. G.; Heinemann, H. Phase transformations of vanadia-titania catalysts induced by phosphoric acid additive. J Catalysis 1989, 120, 457-464.

(27) Ichimura, K.; Sano, M. Electrical conductivity of layered transition-metal phosphorus trisulfide crystals. Synth. Metals 1991, 45, 203-211.

(28) Akiba, K.; Matsubayashi, G.-E.; Tanaka, T. Spectroscopic and electrical properties of oxidized tris(dmit)vanadium anion complexes (dmit = 4,5-dimercapto-1,3-dithiole-2-thionate). Inorg. Chim. Acta 1989, 165, 245-248.

(29) Itti, R.; Wada, T.; Matsuura, K.; Itoh, T.; Ikeda, K.; Yamauchi, H.; Koshizuka, N.; Tanaka, $\mathrm{S}$. Electronic structure of the $\mathrm{BaV} \mathrm{1-x} \mathrm{Ti} \times \mathrm{S} 3$ system as studied by photoelectron spectroscopy. Phys. Rev. B 1991, 44, 2306-2312.

(30) Savenije, T. J.; van Veenendaal, P. A. T. T.; de Haas, M. P.; Warman, J. M.; Schropp R. E. I., Spatially resolved photoconductive properties of profiled polycrystalline silicon thin films. $J$. Appl. Phys. 2002, 91, 5671-5676.

(31) Ho, C.-H. Growth and characterization of near-band-edge transitions in $\beta-\mathrm{In}_{2} \mathrm{~S}_{3}$ single crystals. Journal of Crystal Growth 2010, 312, 2718-2723.

(32) Ho, C.H.; Wang, Y.P.; Chan, C.H.; Huang, Y.S.; Li, C. H. Temperature-dependent photoconductivity in $ß-\mathrm{In}_{2} \mathrm{~S}_{3}$ single crystals. J. Appl. Phys. 2010, 108, 043518.

(33) Nakanishi, H.; Miyashita, H.; Endo, S.; Irie, T. Photoluminescence and photoconduction in the system $\left(\mathrm{CdIn}_{2} \mathrm{~S}_{4}\right)$ 1-X-( $\left.\operatorname{In}_{2} \mathrm{~S}_{3}\right)$ x. J. Appl. Phys. 1981, 20, 1481-1486.

(34) Leroux, M.; Grandjean, N.; Beaumont, B.; Nataf, G.; Semond, F.; Massies, J.; Gibart, P. Temperature quenching of photoluminescence intensities in undoped and doped GaN. J. Appl. Phys. 1999, 86, 3721. 
TOC Graphic
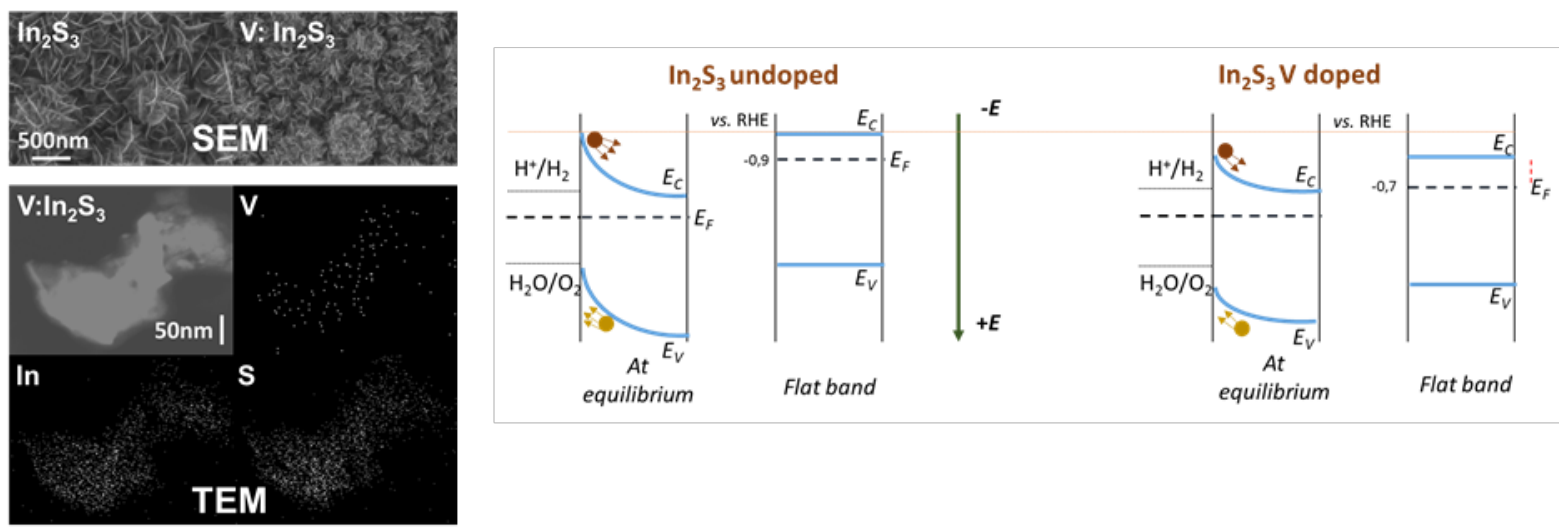